\title{
Protective effect of bronchial challenge with hypertonic saline on nocturnal asthma
}

\author{
M.C. Borges, E. Ferraz, J. Terra-Filho and E.O. Vianna \\ Departamento de Clínica Médica, Faculdade de Medicina de Ribeirão Preto, Universidade de São Paulo, \\ Ribeirão Preto, SP, Brasil \\ Correspondence to: E.O. Vianna, Divisão de Pneumologia, Departamento de Clínica Médica, FMRP, \\ USP, Av. Bandeirantes, 3900, 14048-900 Ribeirão Preto, SP, Brasil \\ Fax: +55-16-3633-6695. E-mail: evianna@uol.com.br
}

\begin{abstract}
Inhalation of hypertonic saline (HS) causes bronchoconstriction in asthmatic subjects. Repeated inhalation of HS leads to substantially reduced bronchoconstriction, known as the refractory period. Refractoriness due to different stimuli has also been described (cross-refractoriness). Nocturnal asthma is defined as an increase in symptoms, need for medication, airway responsiveness, and/or worsening of lung function that usually occurs from 4 to 6 am. Our objective was to determine the effect of refractoriness on nocturnal asthma. The challenge test consisted of inhalations of $4.5 \%$ saline with increasing durations until a reduction of $20 \%$ in forced expiratory volume in $1 \mathrm{~s}\left(\mathrm{FEV}_{1}\right)\left(\mathrm{PD}_{20} \mathrm{HS}\right)$ or total time of $15.5 \mathrm{~min}$. Twelve subjects with nocturnal asthma were challenged with $\mathrm{HS}$ at $16: 00$ and 18:00 $\mathrm{h}$ and $\mathrm{FEV}_{1}$ was measured at 4:00 h. One to 2 weeks later, $\mathrm{FEV}_{1}$ was determined at 16:00 and 4:00 h. LogPD ${ }_{20} \mathrm{HS}$ at 18:00 h was significantly greater than $\log \mathrm{PD}_{20} \mathrm{HS}$ at $16: 00 \mathrm{~h}, 0.51 \pm 0.50$ and 0.69 $\pm 0.60 \mathrm{mg}$, respectively $(P=0.0033)$. When subjects underwent two HS challenges in the afternoon, mean $( \pm S D) F E V_{1}$ reduction was $206 \pm 414 \mathrm{~mL}$ or $9.81 \pm 17.42 \%$. On the control day (without challenge in the afternoon) $\mathrm{FEV}_{1}$ reduction was $523 \pm 308 \mathrm{~mL}$ or $22.75 \pm 15.40 \%(P=0.021)$. Baseline $F E V_{1}$ values did not differ significantly between the control and study days, $2.48 \pm 0.62$ and $2.36 \pm 0.46 \mathrm{~L}$, respectively. The refractory period following HS challenges reduces the nocturnal worsening of asthma. This new concept may provide beneficial applications to asthmatic patients.
\end{abstract}

Key words: Refractory period; Bronchial challenge; Hypertonic saline; Bronchial provocation test

Publication supported by FAPESP.

Received July 31, 2007. Accepted January 25, 2008

\section{Introduction}

Inhalation of hypertonic saline (HS) causes bronchoconstriction in asthmatic subjects (1). Neurogenic reflexes, mediators of inflammatory cells and epithelial cells in the airway mucosa are thought to be involved in this event (2). Over the past 20 years, bronchial challenges with HS have been increasingly used as a relevant test for the diagnosis, assessment of severity and evaluation of treatment of asthma (3). The HS challenge has been shown to be simple, safe and reproducible (4).

After HS-induced bronchoconstriction, asthmatic subjects develop a refractory period during which a second identical challenge induces a substantially reduced bronchoconstriction (5). The refractory period is not a specific phenomenon for HS and its duration and intensity depend on the bronchoconstrictor stimulus (6-9). Refractoriness has been mainly studied as a confounding factor when tests are performed in close sequence and may be used to clarify the pathophysiology of bronchoconstriction, although the mechanisms involved are not understood.

Several studies have demonstrated the presence of cross-refractoriness, a phenomenon whereby a bronchial challenge with one stimulus inhibits the bronchoconstriction induced by another stimulus (10-12). However, no study has investigated cross-refractoriness between a bronchial challenge and the overnight worsening of asthma, a naturally induced bronchoconstriction.

Nocturnal asthma is a common and potentially fatal complication of asthma, defined as an overnight decrease in 
lung function that occurs in association with increased airway hyperresponsiveness $(13,14)$ and airway inflammation (15) compared the awake baseline and leads to nocturnal symptoms such as cough and dyspnea (16). The importance and singularity of nocturnal asthma have led to a search for specific medications and dosing schedules $(17,18)$.

We hypothesized that refractoriness induced in the evening could attenuate the nocturnal worsening of lung function in subjects with nocturnal asthma. Therefore, we determined the effect of HS challenges on the overnight reduction in forced expiratory volume in $1 \mathrm{~s}\left(\mathrm{FEV}_{1}\right)$ of nocturnal asthma.

\section{Subjects and Methods}

\section{Subjects}

Before entry into the study, all subjects were screened by medical history, physical examination, routine laboratory tests, and 1-week peak expiratory flow (PEF) measurements. Twelve subjects participated in the study. All subjects had asthma as defined by the Global Initiative for Asthma (19). They were non-smokers and had an FEV greater than $50 \%$ of their predicted values. None was using theophylline, anticholinergic drugs or had required oral corticosteroids for at least 1 month before entry into the study. Subjects with an upper respiratory tract infection or asthma exacerbation in the last 4 weeks were excluded. All subjects had nocturnal asthma defined as the presence of nocturnal symptoms, with nocturnal awakening and necessity of a bronchodilator, associated with a fall in PEF of $>15 \%$ from bedtime to morning on at least 4 nights over a 7-day period of testing or a mean PEF fall of $>15 \%$ from bedtime to morning over a 7-day period. Patients characteristics are given in Table 1. The study was approved by

Table 1. Subject characteristics and medications.

\begin{tabular}{lc}
\hline Subjects \\
\hline No. of subjects \\
Gender (male/female) & 12 \\
Age (years) & $4 / 8$ \\
$\mathrm{FEV}_{1}(\mathrm{~L})$ & $33 \pm 8$ \\
$\mathrm{FEV}_{1}(\%)$ & $2.48 \pm 0.62$ \\
Medication in use $^{\text {B-agonist (short-acting) }}$ & $74.42 \pm 13.92$ \\
ß-agonist (long-acting) & \\
Inhaled corticosteroids & $9 / 12$ \\
Theophylline & $4 / 12$ \\
Ipratropium bromide & $9 / 12$ \\
\end{tabular}

Age and lung function parameters are reported as mean \pm SD. $\mathrm{FEV}_{1}=$ forced expiratory volume in $1 \mathrm{~s}$. the local Ethics Committee and all subjects gave written informed consent to participate.

\section{Study design}

Subjects attended the laboratory on 2 different days, which were called study and control days. The order of these days was randomized and with an interval of 1-2 weeks. On the study day, the asthmatics were submitted to HS challenge at 16:00 and at 18:00 h. No medications were given after each challenge, and the spontaneous recovery of $\mathrm{FEV}_{1}$ was measured. During the same night, at 4:00 h, the $F E V_{1}$ was assessed by spirometry to calculate the nocturnal reduction of $\mathrm{FEV}_{1}$. On the control day, $\mathrm{FEV}_{1}$ was measured at 16:00 $\mathrm{h}$ and inhalation of isotonic saline was performed after this spirometry (sham challenge). During the same night, $\mathrm{FEV}_{1}$ was assessed at 4:00 $\mathrm{h}$ to calculate the nocturnal reduction of $\mathrm{FEV}_{1}$. The control day was used to determine the basal overnight reduction in $\mathrm{FEV}_{1}$. No medications were taken between 16:00 and 4:00 h. After each test, subjects were asked to record their respiratory symptoms. Inhaled short-acting ß-agonists were stopped for at least $12 \mathrm{~h}$ and long-acting ß-agonists were stopped for $24 \mathrm{~h}$ before the study procedures. The use of inhaled corticosteroids was not stopped.

\section{Hypertonic saline challenge}

The HS challenge was performed using an ultrasonic nebulizer (DeVilbiss Ultra-Neb 2000, DeVilbiss, Somerset, PA, USA) calibrated to produce an aerosol output of at least $1.5 \mathrm{~mL} / \mathrm{min}$. $\mathrm{HS}(4.5 \% \mathrm{NaCl}, \mathrm{w} / \mathrm{v})$ was prepared by dilution of commercial sterile preservative-free $20 \%$ saline. The aerosol was delivered to the patient by a two-way non-rebreathing valve (Hans Rudolph 2700 series, Kansas City, MO, USA) through $100-\mathrm{cm}$ long tubing with an internal diameter of 2.2 $\mathrm{cm}$. Previous studies have shown that the output of this nebulizer system ranges from 1.9 to $2.5 \mathrm{~mL} / \mathrm{min}$ at tidal volumes of $300-500 \mathrm{~mL}$ and respiratory rates of $12-20 / \mathrm{min}$, with a particle size distribution of median mass aerodynamic diameter between 2.33 and $2.87 \mu \mathrm{m}$ and with $100 \%$ of the particles being less than $5 \mu \mathrm{m}$ in diameter (20).

After three reproducible measurements of baseline $\mathrm{FEV}_{1}$, subjects breathed through the valve with the nebulizer switched off for 2 min, $\mathrm{FEV}_{1}$ measurement was repeated, and then HS inhalation was initiated with a first exposure period of $30 \mathrm{~s}$. After this first inhalation, subjects breathed increasing doses of HS by doubling the duration of nebulization $(0.5,1,2,4$, and $8 \mathrm{~min})$. FEV 1 was measured in duplicate $90 \mathrm{~s}$ after each inhalation. If the $\mathrm{FEV}_{1}$ reduced less than $10 \%$ of the baseline value, the exposure time was doubled. If the reduction of $\mathrm{FEV}_{1}$ was more than $10 \%$ and less than $20 \%$, the exposure time was repeated 
rather than doubled. The test was stopped when a reduction of $20 \%$ or more of $\mathrm{FEV}_{1}$ was obtained or after a total exposure of $15.5 \mathrm{~min}$. The aerosol output was determined by weighing the canister and tubing on an electronic scale (AS 2000, Marte, São Paulo, SP, Brazil) before and after the challenge tests. Patients were asked about the intensity of dyspnea at each inhalation by using a scale from 0 to 3 , where 0 meant no dyspnea; 1 , mild dyspnea; 2 , moderate dyspnea, and 3, severe dyspnea. The tests were performed with a Koko spirometer and software (PDS Instrumentation, Inc., Louisville, CO, USA).

\section{Expression of airway responsiveness and refractory period}

We plotted $\mathrm{FEV}_{1}$ results (ordinate) against HS dose (abscissa) in order to construct a dose-response curve. The dose required to produce a $20 \%$ reduction in $\mathrm{FEV}_{1}$ $\left(\mathrm{PD}_{20} \mathrm{HS}\right)$ was calculated by linear interpolation between the last two values.

The refractory period was determined by comparing the $\mathrm{PD}_{20} \mathrm{HS}$ at $16: 00 \mathrm{~h}$ with the $\mathrm{PD}_{20} \mathrm{HS}$ at $18: 00 \mathrm{~h}$ on the study day. To quantify the HS refractoriness, a refractory index was calculated by dividing the $16: 00-\mathrm{h} \mathrm{PD}_{20} \mathrm{HS}$ by the 18:00-h $\mathrm{PD}_{20} \mathrm{HS}(21)$.

Effect of refractoriness on the overnight $\mathrm{FEV}_{1}$ reduction

The effect of refractoriness on the overnight $F E V_{1}$ reduction was determined by comparing the $\mathrm{FEV}_{1}$ reduction from 16:00 to 4:00 $\mathrm{h}$ on the control day (basal reduction) with the $\mathrm{FEV}_{1}$ reduction from 16:00 to $4: 00 \mathrm{~h}$ on the study day.

Spontaneous recovery of $\mathrm{FEV}_{\mathbf{1}}$

The recovery time (spontaneous recovery of $\mathrm{FEV}_{1}$ ) was obtained by measuring $\mathrm{FEV}_{1}$ every $5 \mathrm{~min}$ after the challenge during the first hour and then at 15-min intervals until $\mathrm{FEV}_{1}$ spontaneously returned to $90 \%$ of the basal value.

\section{Statistical analysis}

The baseline $\mathrm{FEV}_{1}$ measurements before the bronchial challenges and at 16:00 $\mathrm{h}$ on the study and control days were compared by the Student $t$-test. $\mathrm{PD}_{20} \mathrm{HS}$ values were log transformed and compared by the two-tailed paired Student $t$-test. The overnight reduction in $\mathrm{FEV}_{1}$ and the recovery time were also compared by the two-tailed paired Student $t$-test.

\section{Results}

Repeated challenge of the airways with HS resulted in loss of airway responsiveness. The $\log \mathrm{PD}_{20} \mathrm{HS}$ at 18:00 $\mathrm{h}$ $(0.69 \pm 0.60 \mathrm{mg})$ was significantly greater than the $\log \mathrm{PD}_{20} \mathrm{HS}$ at $16: 00 \mathrm{~h}(0.51 \pm 0.50 \mathrm{mg} ; \mathrm{P}=0.0033)$. The mean refractory index was $1.66 \pm 0.57$ and ranged from 0.68 to 2.35. Baseline $\mathrm{FEV}_{1}$ values did not differ significantly between the 16:00- and 18:00-h bronchial challenge, $2.36 \pm 0.46$ and $2.31 \pm 0.49 \mathrm{~L}$, respectively.

The overnight reduction of $\mathrm{FEV}_{1}$ was significantly greater on the control day than on the study day (Figures 1 and 2).

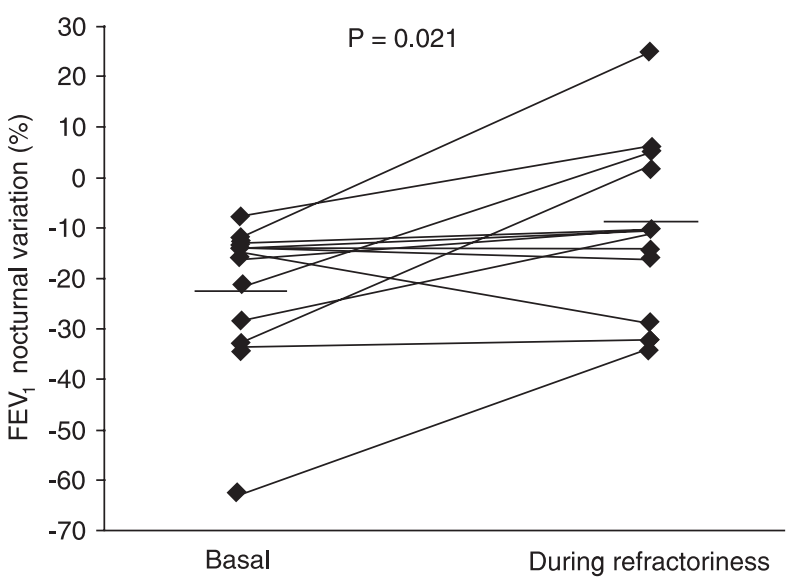

Figure 1. Overnight forced expiratory volume in $1 \mathrm{~s}\left(\mathrm{FEV}_{1}\right)$ variation on the control and study days. $\mathrm{FEV}_{1}$ nocturnal variation (reported as percent of basal value) of 12 asthmatic subjects on the control day (basal FEV 1 overnight reduction) and study day (following challenges). On the study day, subjects underwent hypertonic saline challenges at 16:00 and 18:00 h. The horizontal lines indicate the means.

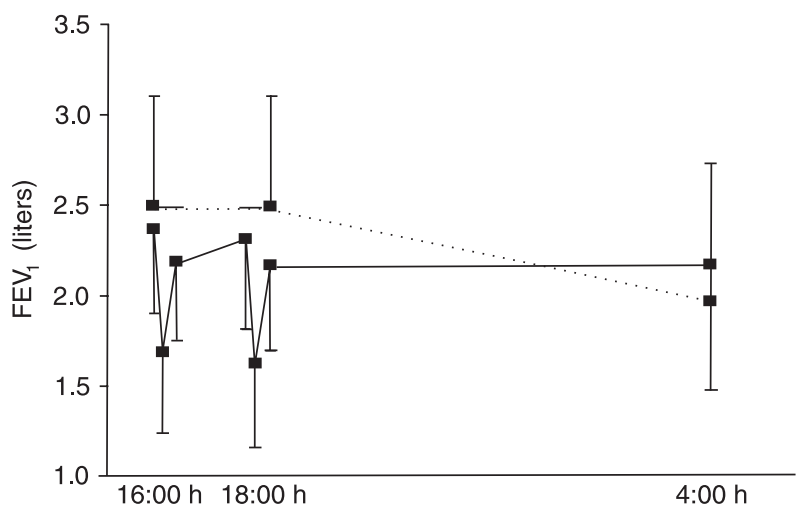

Figure 2. Variation of forced expiratory volume in $1 \mathrm{~s}\left(\mathrm{FEV}_{1}\right)$ on the control and study days. $\mathrm{FEV}_{1}$ is reported in liters from 16:00 to $4: 00 \mathrm{~h}$ for 12 asthmatic subjects on 2 days. On the control day (dotted line) the asthmatics inhaled isotonic saline and on the study day (solid line) they underwent hypertonic saline challenges at 16:00 and 18:00 h. No medications were taken between $16: 00$ and $4: 00 \mathrm{~h}$. 
The mean overnight reduction of $\mathrm{FEV}_{1}$ was $523 \pm 308 \mathrm{~mL}$ or $22.75 \pm 15.40 \%$ on the control day and $206 \pm 414 \mathrm{~mL}$ or $9.81 \pm 17.42 \%$ on the study day, i.e., during the refractory period $(P=0.021)$. Baseline $F E V_{1}$ values did not differ significantly between the control and study days, $2.48 \pm$ 0.62 and $2.36 \pm 0.46 \mathrm{~L}$, respectively.

The mean recovery time after the 16:00-h HS challenge was $37.50 \pm 21.58 \mathrm{~min}$ and ranged from 10 to $70 \mathrm{~min}$. The mean recovery time after the 18:00-h HS challenge was $31.67 \pm 27.83 \mathrm{~min}$ and ranged from 5 to $90 \mathrm{~min}$. The recovery time after the 16:00-h HS challenge did not differ significantly from the recovery time after the 18:00-h HS challenge. After the spontaneous recovery, $\mathrm{FEV}_{1}$ returned to $2.18 \pm 0.43$ and $2.16 \pm 0.46 \mathrm{~L}$, following $16: 00$ and $18: 00$ h challenges, respectively (Figure 2 ).

All subjects reported 0 (zero) for dyspnea before the challenge. The highest degree (score 3 ) was observed in two $(17 \%)$ subjects, occurring after the final inhalation. The $\mathrm{HS}$ inhalation and the recovery time were well tolerated, with very few side effects.

\section{Discussion}

This study demonstrated that performing HS challenges in the evening considerably reduces the overnight $\mathrm{FEV}_{1}$ fall in subjects with nocturnal asthma. Since no medications were taken between 16:00 and 4:00 h, the improvement in nocturnal bronchoconstriction could not be due to additional use of rescue medication. The protection may be explained by refractoriness. The rationale for this explanation is the cross-refractoriness that has been described among the various bronchoconstrictor stimuli $(5,10-12)$. The mechanisms of nocturnal asthma are complex and have only been partially elucidated (22). Thus, some pathway that is able to induce a bronchospasm and refractory period could be shared between nocturnal and induced bronchospasms.

To provide mechanistic insight for the observations presented, a different group of 13 asthmatics in a controlled and randomized protocol underwent $\mathrm{HS}$ challenge at 7:00 and 17:00 $\mathrm{h}$ and, on another day, at 17:00 $\mathrm{h}$ (control). The $\mathrm{PD}_{20}$ at $17: 00 \mathrm{~h}$ on the study day was significantly greater than the $\mathrm{PD}_{20}$ at 17:00 $\mathrm{h}$ on the control day (Borges MC, Ferraz E, Terra-Filho J, Vianna EO, unpublished results). Therefore, the duration of the refractory period following hypertonic saline challenges was at least $10 \mathrm{~h}$, which is compatible with the protection observed in the present study.

Some other studies have evaluated the duration of the refractory period. For methacholine, refractoriness has been demonstrated to last $24 \mathrm{~h}$ in non-asthmatic subjects
(23) and in asthmatics subjects (6). Schmidt et al. (7) have shown 3-day tachyphylaxis after bradykinin challenges. Previous studies on HS challenges demonstrated the occurrence of refractoriness, but not its duration. Further studies are necessary to determine the entire duration of this phenomenon after an HS challenge.

Non-isotonic solutions cause bronchoconstriction in asthmatic subjects by several mechanisms: change in airway osmolarity or ion concentration, mast cell degranulation, airway epithelial alteration, airway smooth muscle contraction, and inflammatory cell and sensory nerve activation $(2,24)$. Although the present study reports for the first time the cross-refractoriness between a bronchial saline challenge and the overnight worsening of asthma, the precise explanation for this phenomenon will depend on a multi-factorial approach, probably with animal models. The pathophysiology of the refractory period has been investigated for approximately 30 years and has not been fully elucidated. Several mechanisms have been evaluated, with no evidence of mast cell mediator depletion (21), catecholamine production (25) or a direct action on smooth muscle (26).

The production of inhibitory prostanoids and neural mechanisms is a possible mechanism. Some studies have demonstrated that the release of inhibitory prostaglandins, probably $\mathrm{PGE}_{2}$, could have an important role in refractoriness since pre-treatment with indomethacin reduced the refractory period in response to some bronchoconstrictor stimuli $(27,28)$. Other studies have demonstrated that $\mathrm{PGE}_{2}$ has a bronchodilator and anti-inflammatory effect and reduces airway responsiveness (29).

The contribution of neural mechanisms to the refractory period has been shown in some studies. Rajakulasingam et al. (11), in 1995, demonstrated cross-refractoriness between HS and bradykinin challenges and speculated that these two agonists produced refractory periods through similar pathways. Since neural mechanisms have an important role in bradykinin-induced bronchoconstriction, they probably also contributed to the refractory period (11).

In addition to the pathophysiological relevance, the implications of these findings are quite extensive. These results create a need for further investigations in order to understand the clinical relevance of the phenomenon demonstrated. HS has some benefits in the treatment of allergic rhinitis and cystic fibrosis $(30,31)$ and a salt chamber has been shown to be beneficial to asthmatic patients (32). Since bronchial challenge with exercise has some similarity to HS challenge, we may also speculate on the effect of exercise bronchoconstriction on nocturnal asthma. Nevertheless, in view of the refractoriness following exercise- 
induced bronchospasm, it has been reported that exercise is useful for asthmatics (33).

The recovery of bronchospasm and the risk of late asthmatic reaction are issues related to the safety of employing challenge tests. We have shown here rapid, spontaneous and well-tolerated recovery with no need for a bronchodilator. Moreover, up to $10 \mathrm{~h}$ after the HS challenge there was no evidence of a late asthmatic reaction.

HS challenges applied in the evening attenuated the overnight reduction of $\mathrm{FEV}_{1}$ in patients with nocturnal asthma. This observation shows for the first time a new and interesting concept. This protection may be attributed to the release/production of inhibitory prostanoids, to neural mechanisms, reduction of airway responsiveness and/ or action on neurogenic inflammation. Further studies are necessary to elucidate these mechanisms and the clinical implications of refractoriness induced by HS in asthma.

\section{References}

1. Schoeffel RE, Anderson SD, Altounyan RE. Bronchial hyperreactivity in response to inhalation of ultrasonically nebulised solutions of distilled water and saline. $\mathrm{Br}$ Med J (Clin Res Ed) 1981; 283: 1285-1287.

2. Smith $\mathrm{CM}$, Anderson SD. Inhalation provocation tests using nonisotonic aerosols. J Allergy Clin Immunol 1989; 84: 781790.

3. Anderson SD, Brannan JD. Methods for "indirect" challenge tests including exercise, eucapnic voluntary hyperpnea, and hypertonic aerosols. Clin Rev Allergy Immunol 2003; 24: 27-54.

4. Riedler J, Gamper A, Eder W, Oberfeld G. Prevalence of bronchial hyperresponsiveness to $4.5 \%$ saline and its relation to asthma and allergy symptoms in Austrian children. Eur Respir J 1998; 11: 355-360.

5. Belcher NG, Rees PJ, Clark TJ, Lee TH. A comparison of the refractory periods induced by hypertonic airway challenge and exercise in bronchial asthma. Am Rev Respir Dis 1987; 135: 822-825.

6. Beach JR, Stenton SC, Connolly MJ, Walters EH, Hendrick DJ. Effects of diurnal variation and prolonged refractoriness on repeated measurements of airways responsiveness to methacholine. Thorax 1995; 50: 235-239.

7. Schmidt D, Jorres RA, Rabe KF, Magnussen H. Tachyphylaxis of airway response to inhaled bradykinin over several days. Pneumologie 1996; 50: 779-782.

8. Beckett WS, Marenberg ME, Pace PE. Repeated methacholine challenge produces tolerance in normal but not in asthmatic subjects. Chest 1992; 102: 775-779.

9. Strban M, Manning PJ, Watson RM, O'Byrne PM. Effect of magnitude of airway responsiveness and therapy with inhaled corticosteroid on histamine tachyphylaxis in asthma. Chest 1994; 105: 1434-1438.

10. Pavord I, Lazarowicz H, Inchley D, Baldwin D, Knox A, Tattersfield A. Cross refractoriness between sodium metabisulphite and exercise induced asthma. Thorax 1994; 49: 245-249.

11. Rajakulasingam $\mathrm{K}$, Makker HK, Howarth $\mathrm{PH}$, Holgate ST. Cross refractoriness between bradykinin and hypertonic saline challenges in asthma. J Allergy Clin Immunol 1995; 96: 502-509.

12. Groot C, Lammers JW, Festen J, van Herwaarden C. Refractoriness for ultrasonically nebulized distilled water and histamine after histamine challenge. J Appl Physiol 1991; 70: 1011-1015.
13. Martin RJ, Cicutto LC, Ballard RD. Factors related to the nocturnal worsening of asthma. Am Rev Respir Dis 1990; 141: 33-38.

14. Ferraz E, Borges MC, Terra-Filho J, Martinez JA, Vianna EO. Comparison of $4 \mathrm{AM}$ and $4 \mathrm{PM}$ bronchial responsiveness to hypertonic saline in asthma. Lung 2006; 184: 341346.

15. Kraft M, Djukanovic R, Wilson S, Holgate ST, Martin RJ. Alveolar tissue inflammation in asthma. Am J Respir Crit Care Med 1996; 154: 1505-1510.

16. Sutherland ER. Nocturnal asthma. J Allergy Clin Immunol 2005; 116: 1179-1186.

17. Beam WR, Weiner DE, Martin RJ. Timing of prednisone and alterations of airways inflammation in nocturnal asthma. Am Rev Respir Dis 1992; 146: 1524-1530.

18. Reinberg A, Gervais P, Chaussade M, Fraboulet G, Duburque B. Circadian changes in effectiveness of corticosteroids in eight patients with allergic asthma. J Allergy Clin Immunol 1983; 71: 425-433.

19. National Heart Lung and Blood Institute. Global initiative for asthma. Global strategy for asthma management and prevention. Bethesda: National Heart Lung and Blood Institute; 2002.

20. Riedler J, Robertson CF. Effect of tidal volume on the output and particle size distribution of hypertonic saline from an ultrasonic nebulizer. Eur Respir J 1994; 7: 998-1002.

21. O'Hickey SP, Rees PJ, Lee TH. Airway responsiveness to adenosine $5^{\prime}$ monophosphate following inhalation of hypertonic saline. Eur Respir J 1989; 2: 923-928.

22. Vianna EO. Mechanisms and therapeutic implications of asthma circadian rhythm. Curr Respir Med Rev 2005; 1: 171-183.

23. Beckett WS, McDonnell WF III, Wong ND. Tolerance to methacholine inhalation challenge in nonasthmatic subjects. Am Rev Respir Dis 1988; 137: 1499-1501.

24. Joos GF, O'Connor B, Anderson SD, Chung F, Cockcroft DW, Dahlen B, et al. Indirect airway challenges. Eur Respir J 2003; 21: 1050-1068.

25. Belcher NG, Murdoch R, Dalton N, Clark TJ, Rees PJ, Lee $\mathrm{TH}$. Circulating concentrations of histamine, neutrophil chemotactic activity, and catecholamines during the refractory period in exercise-induced asthma. J Allergy Clin Immunol 1988; 81: 100-110.

26. Hahn AG, Nogrady SG, Tumilty DM, Lawrence SR, Morton AR. Histamine reactivity during the refractory period after 
exercise induced asthma. Thorax 1984; 39: 919-923.

27. Hawksworth RJ, O'Hickey SP, Lee TH. The effects of indomethacin on the refractory period to hypertonic saline-induced bronchoconstriction. Eur Respir J 1992; 5: 963-966.

28. O'Byrne PM, Jones GL. The effect of indomethacin on exercise-induced bronchoconstriction and refractoriness after exercise. Am Rev Respir Dis 1986; 134: 69-72.

29. Gauvreau GM, Watson RM, O'Byrne PM. Protective effects of inhaled PGE2 on allergen-induced airway responses and airway inflammation. Am J Respir Crit Care Med 1999; 159: 31-36.

30. Eng PA, Morton J, Douglass JA, Riedler J, Wilson J, Robertson CF. Short-term efficacy of ultrasonically nebulized hypertonic saline in cystic fibrosis. Pediatr Pulmonol 1996; 21: 77-83.

31. Garavello W, Romagnoli M, Sordo L, Gaini RM, Di Berardino $\mathrm{C}$, Angrisano A. Hypersaline nasal irrigation in children with symptomatic seasonal allergic rhinitis: a randomized study. Pediatr Allergy Immunol 2003; 14: 140-143.

32. Hedman J, Hugg T, Sandell J, Haahtela T. The effect of salt chamber treatment on bronchial hyperresponsiveness in asthmatics. Allergy 2006; 61: 605-610.

33. McKenzie DC, McLuckie SL, Stirling DR. The protective effects of continuous and interval exercise in athletes with exercise-induced asthma. Med Sci Sports Exerc 1994; 26: 951-956. 